San Jose State University

SJSU ScholarWorks

Master's Projects

Master's Theses and Graduate Research

$5-1-2009$

\title{
English Language Acculturation and Academic Achievement Among Junior Year Nursing Students
}

Leah Lukrich

San Jose State University

Follow this and additional works at: https://scholarworks.sjsu.edu/etd_projects

Part of the Other Nursing Commons

\section{Recommended Citation}

Lukrich, Leah, "English Language Acculturation and Academic Achievement Among Junior Year Nursing Students" (2009). Master's Projects. 784.

DOI: https://doi.org/10.31979/etd.mj9d-7ajr

https://scholarworks.sjsu.edu/etd_projects/784

This Master's Project is brought to you for free and open access by the Master's Theses and Graduate Research at SJSU ScholarWorks. It has been accepted for inclusion in Master's Projects by an authorized administrator of SJSU ScholarWorks. For more information, please contact scholarworks@sjsu.edu. 


\section{SAN JOSE STATE UNIVERSITY SCHOOL OF NURSING}

\section{MASTER'S PROGRAM PROJECT OPTION (PLAN B) PROJECT SIGNATURE FORM}

STUDENT NAME

SEMESTER ENROLLED

TITLE OF PROJECT

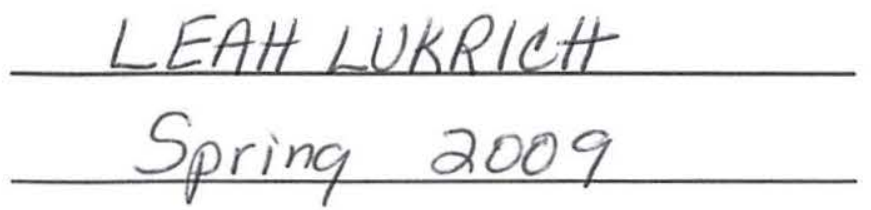

ENGLISH LANGUAGE

ACCULTURATION AMONG JUNIOR

YEAR NURSING STUDENTS

\section{NAME OF JOURNAL}

$$
\frac{\text { JOURNAL OF NORSING }}{\text { EDUCATION }}
$$

The project and the manuscript have been successfully completed and meet the standards of the School of Nursing University. The project demonstrates the application of professional knowledge, clinical expertise, and scholarly thinking. An abstract of the project and two copies of the manuscript are attached.

$$
\text { Din aetre }
$$

\section{ADVISOR'S SIGNATURE}

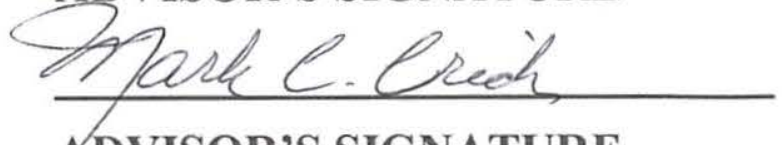

ADVISOR'S SIGNATURE

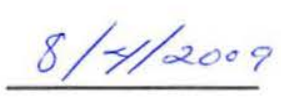

DATE

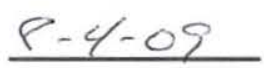

DATE

Please submit the form to the Graduate Coordinator. Attach abstract, two copies of the manuscript, and the documentation of submission to the journal (i.e., postal receipt). 


\title{
English Language Acculturation And Academic Achievement \\ Among Junior Year Nursing students
}

\author{
Leah Lukrich, MS, RN \\ Diane Stuenkel, EdD, RN \\ Mark Crider, PhD, RN
}

\begin{abstract}
Efforts to alleviate the current nursing shortage have focused on recruitment and retention of diverse nursing students. Language acculturation has been identified in the literature as one predictor of academic achievement (Salamonson et al, 2008) PURPOSE: This study examined the relationship between pathophysiology and pharmacology grades and scores on the English Language Acculturation Scale (ELAS) survey for junior-level nursing students $(\mathrm{N}=65)$. The relationship between years living in the United States (U.S.) and pathophysiology and pharmacology grades was examined also. RESULTS: ELAS scores ranged from 7-25, with a mean of $22(\mathrm{SD}=4.27)$. No statistically significant correlation was found between pathophysiology or pharmacology grades and ELAS score. A weak correlation was identified between length of time lived in the U.S. and pathophysiology grades $(r=.260, p<.05)$ and pharmacology grades $(r=.288, p<.05)$. For this sample, success in pharmacology and pathophysiology coursework paralleled linguistic competence.
\end{abstract}


English Language Acculturation and

Academic Achievement Among Junior Year

Nursing Students

Leah Lukrich MS, RN, Diane Stuenkel EdD, RN, and Mark Crider PhD, RN

San Jose State University School of Nursing 


\begin{abstract}
Efforts to alleviate the current nursing shortage have focused on recruitment and retention of diverse nursing students. Language acculturation has been identified in the literature as one predictor of academic achievement (Salamonson et al, 2008) PURPOSE: This study examined the relationship between pathophysiology and pharmacology grades and scores on the English Language Acculturation Scale (ELAS) survey for junior-level nursing students $(N=65)$. The relationship between years living in the United States (U.S.) and pathophysiology and pharmacology grades was examined also. RESULTS: ELAS scores ranged from 7-25, with a mean of $22(\mathrm{SD}=4.27)$. No statistically significant correlation was found between pathophysiology or pharmacology grades and ELAS score. A weak correlation was identified between length of time lived in the US and pathophysiology grades $(r=.260, p<.05)$ and pharmacology grades $(r=.288, p<.05)$. For this sample, success in pharmacology and pathophysiology coursework paralleled linguistic competence.
\end{abstract}




\section{English Language Acculturation and}

\section{Academic Achievement Among Junior Year Nursing Students}

In the foreseeable future the composition of the United States (U.S.) will change.

By the year 2050, the non-Hispanic White culture is projected to decline to $46.3 \%$ of the U.S. populace and culturally distinct minority groups will increase to make up $53.6 \%$ of the U.S. populace (U.S. Census Bureau, 2000). This statistic has implications for our society and health care infrastructure, which is entrusted with providing access to quality health care for all (U.S. Department of Health and Human Services (HHS), 2000, p.16). Increasing minority representation in the health professions is based on studies showing that minority health professionals " are likely to serve in areas with high proportion of underrepresented racial and ethnic groups and to practice in or near health care shortage areas."(Healthy People 2010, n.d., focus area 1-8, para 4) The proposition that diverse healthcare providers must be an integral part of health care delivery to a diverse citizenry is encapsulated in nursing schools' desire to recruit and retain diverse nursing students (Davidhizar \& Shearer, 2005; Guhde, 2003; Schwartz, 2008; Kennedy, Fisher, Fontaine, \& Marin-Holland, 2008). Creative teaching strategies, innovative curricula, and ethnically diverse faculty will be vital to ensure the academic success of students with unique cultural and linguistic abilities (Yoder, 2001).

Given the increasing presence of diversity among nursing students, consideration of the interrelationships between English language proficiency and academic subject achievements is warranted (Davidhizar \& Shearer, 2005: Lujan, 2008; Salamonson, Everett, Koch, Andrew, \& Davidson, 2008). As a first step, nursing programs should be prepared to assess for academic 
English language proficiency and recognize barriers to its attainment. The purposes of this study were threefold: (a) to describe the degree of English language acculturation as measured by the English Language Acculturation Scale (ELAS) for a subset of junior-level nursing students, (b) to determine if a statistically significant correlation existed between ELAS scores and pathophysiology and pharmacology grades, and (c) to determine if there was a statistically significant correlation between years residing in the United States and academic achievement as measured by pathphysiology and pharmacology grades.

\section{SECOND LANGUAGE AND ACCULTURATION}

An outcome of multiculturalism is a phenomena referred to in social psychology literature as acculturation. Redfield, Linton, and Herskovits (1936) defined the process of acculturation as “ those phenomena, which result when groups of individuals having different cultures come into continuous first-hand contact." (as cited in Noels, Pon, \& Clement, 1996, p.247). Embedded amid the multifactorial experience (e.g. customs behaviors, and participation in the native community) of acculturation is the variable of second-language competence and its position as a strong indicator of " linguistic acculturation and...mediator of the stresses of acculturative contact." (Noels et al, p.249).

Second language learning, according to Cummins' model of language acquisition, is divided into everyday conversational speech (BICS) and cognitive academic language (CALP). Within institutions of higher education academic English is highly valued and functions to facilitate discipline specific discourse (Scarcella, 2003). English as Second Language (ESL) learners, according to Scarcella (2003) often lack sufficient academic English proficiency to compete 
successfully in post-secondary institutions. Assessment of English language proficiency is mandated for California public school students in grades K-12 (Solorzano, 2008). Extending this mandate, Scarcella (2003) emphasized that academic English must be fostered in the elementary and secondary grades and students who live in communities where CALP is not taught or spoken will have no occasion to acquire this skill set.

Academic language is seen as a barrier for ESL nursing students and the academic achievements of the ESL student can be impeded if appropriate support and teaching strategies are not created (Abriam -Yago, Yoder, \& Kataoka-Yahiro, 1999; Lujan, 2008; Bosher \& Bowles, 2008). Salamonson et al. (2008) found that academic performance of ESL nursing students was related to their English Language Acculturation Scale (ELAS) scores and that length of residence was also related to ELAS scores. High stakes tests for ESL learners are considered difficult, flawed and linguistically biased due to test item construction (Lujan; Bosher \& Bowles). ESL learners are difficult to quantify and identification of ESL students at California State University campuses is accomplished using placement tests, self-identification, and visa information (Intersegmental Committee of Academic Senates (ICAS) Task Force, 2006). Students who encounter under preparedness in English language skills, including but not limited to comprehension, orthology, grammar, and semantics, will have to surmount many real world obstacles once they are finished with their education and prepare for licensing examinations. Higher education is obliged to address language disparities to ensure that future students in the U.S. have a solid foundation from which to be effective health practitioners. 
Methods

\section{Design}

A descriptive design was used to quantitatively measure the linguistic preferences of a subset of diverse nursing students. Measurement scores were calculated and subjected to statistical analysis using a two-tailed Pearsons coefficient correlation. Means and standard deviations were also obtained for dependant and independent variables.

\section{Sample and Setting}

A convenience sample of junior level nursing students $(\mathrm{N}=79)$ in a Baccalaureate Nursing program at a public university in northern California were invited to participate. Recent completion of pathophysiology and pharmacology courses established the inclusion criteria. Sixty-five students completed a paper/pencil survey during the Spring 2009 semester ( $81 \%$ response rate).

\section{INSTRUMENT}

The ELAS (Salamonson et al., 2008) survey, along with a questionnaire requesting demographic data (age, gender, ethnicity, years in U.S, employment) were distributed. A 5-item survey instrument, the ELAS has a reported Cronbach's alpha of .89 (Salamonson, Everett, Koch, Andrew, \& Davidson, 2008). Permission to use the 5-item ELAS instrument was obtained from Dr. Yenna Salamonson (2008) for education and research purposes, excluding any modification or revisions. ELAS was adapted from a larger, validated acculturation scale, the Short Acculturation Scale for Hispanics (Salamonson et al, 2008). The 5-item survey consisted 
of the following questions:(a) In general, what language(s) do you speak? (b) In general, what language(s) do you read? (c) What language(s) do you usually speak at home? (d) In which language(s) do you usually think? (e) What language(s) do you usually speak with friends? Each question had five responses from which to choose only one answer: (a) Only non-English language(s); More non-English than English; (c) Both non-English and English equally; (d) More non-English than English; (d) Only non-English language(s). Values were assigned to each response, ranging from 1-5 (1/low= Only non-English language(s) to 5/high= Only English language(s). Possible ELAS scores ranged from 5-25.

Students self-reported pharmacology and pathophysiology grades from the prior semester.

\section{Procedure}

University Institutional Review Board for Human Subjects approval was obtained. Prior to the collection of data the investigator informed the students of the purpose and features of the study and measurement instrument. Written consent was obtained and participants completed the surveys after their regular skills lab session.

Results

\section{Description of Sample}

Females accounted for $84 \%$ of the participants. Ages ranged from $20-49$ years with a mean of 24.7 years. Mean grade point average (GPA) for pharmacology was 3.4 with a mode of 4.0; mean GPA for pathophysiology was 3.15 with a mode of 3.0 . Seventy-five percent of the participants were born in the U.S. Approximately $35 \%$ were non-Hispanic White students, $27.7 \%$ 
were Filipino, $21.5 \%$ Asian pacific islander, $6.2 \%$ African- American, and Hispanic/Latinos made up $9.6 \%$.

Description of ELAS Scores and Correlations to Grades

After summing the values for each item, ELAS scores were grouped into thirds: Low (5-13), Medium (14-18), and High (19-25) ranges. For the sample ( $n=64,1=$ missing data) surveyed, ELAS scores ranged from 7-25 $(X=22, \mathrm{SD}=4.27)$. Four students $(6.2 \%)$ scored in the Low range (5-13), eight (12.6\%) in the Medium range (14-18), and fifty-two students (81.2\%) were in the high range $(19-25)$. No statistically significant correlation was found between ELAS scores and pathophysiology, and ELAS scores and pharmacology.

Description of Years Lived in United States (U.S.) and Correlation to Grades

Seventy-five percent $(\mathrm{N}=49)$ of the students surveyed were born in the U.S. The mean number of years lived in the U.S. was 22.5 (6.9). A weak correlation was found between pathophysiology grades and years lived in the U.S. $(r=.260, p<.05)$ and a weak correlation was found between pharmacology grades and years lived in the U.S. $(r=.288, p<.05)$.

\section{Description of English Fluency}

When asked to list language fluency in terms of speaking, reading, and writing, $90.6 \%$ speak English fluently, 92\% read English fluently, and 95.3\% write English fluently.

\section{Discussion}

The first research question this study sought to answer was the level of language acculturation for a sample of junior year nursing students, as measured by the ELAS survey. The ELAS 
(Salamonson et al., 2008) is a measurement tool of language preference and language usage frequency. The results of the ELAS survey confirmed high levels of English language acculturation and English language use among this cohort. Moreover, greater than $90 \%$ of the sample considered themselves fluent in English reading, writing and speaking. At the University, English language proficiency is assessed using English language placement tests and is a criterion of admission. Early identification of English under preparedness is intended to improve recruitment and retention. The assessment of language readiness for university coursework can be achieved using more precise robust tools of measurement.

No statistically significant correlation between course grades in pathophysiology and pharmacology subjects and levels of language acculturation was found. Not surprisingly, high levels of English language acculturation parallels academic success for this sample of junior year nursing students. Language skill competence is a factor in predicting psychological and cultural adjustment into the dominant culture and is supported by theoretical and empirical studies (Kang, 2006; Noels et al., 1996). English language proficiency exceeds other cultural factors in predicting cultural adjustment. However, to what extent language acculturation correlates to academic success is unclear. Salamonson and colleagues (2008) found that language acculturation levels were statistically related to course failure among ESL students in one baccalaureate-nursing program. Research by Sowden (2003) argued that study habits of international students do not imitate Western students' practices. These students were often unsuccessful because their native culture did not stimulate self-directed learning and critical thinking skills according to Western standards (Sowden). Scarcella (2003) pointed out that students who develop academic English language skills also possess sufficient background 
knowledge that," helps fill in gaps in communication and interpret ambiguous messages."(p.25). Factors such as motivation, time management, educational resources, and socio-economic status are known to influence academic success.

The final research question explored the correlation between length of time lived in the US and course grades. A weak statistical correlation was identified between pathophysiology $(r=.260, p<.05)$ and pharmacology $(r=.288, p<.05)$ grades and length of time lived in the U.S. $(X=22 y e a r s, ~ S D=6.91)$. For this sample, approximately $9 \%$ of the variance in course grades was accounted for by length of time in the U.S. In aforementioned research, language acculturation levels, as measured by the ELAS scores were positively correlated to length of residence among first year nursing students in Australia (Salamonson, 2008).

\section{Limitations}

Results from this study should be generalized with caution. This study used convenience sampling without identification of ESL status. Comparing success rates between ESL and nonESL nursing students may yield different results. Moreover, completion of the ELAS survey and reporting of pathophysiology/pharmacology grades took place one semester after the courses were finished. Students' perceptions of individual language acculturation may have changed during the intervening time. 


\section{Conclusions}

Language acculturation as measured by language preference and usage is considered a factor in academic language proficiency and, ostensibly, contributes to academic achievement. Reaching out to ESL students and employing traditional and innovative teaching/learning strategies will assist students in using English effectively in their academic work. Reducing language difficulties and improving communication competence will help overcome language barriers for ESL students. 


\section{References}

Abriam-Yago, K., Yoder, M., \& Katoako-Yahiro, M. (1999). The Cummins model:

A framework for teaching nursing students for whom English is a second language. Journal of Transcultural Nursing, 10(2), 143-149.

Bosher, S., \& Bowles, M. (2008). The effects of linguistic modification on ESL students' comprehension of nursing course test items. Nursing Education Perspectives, 29(3), $165-172$.

Davidhizar, R., \& Shearer, R. (2005). When your nursing student is culturally diverse. The Health Care Manager, 24(4), 356-363.

Guhde, J. A. (2003). English-as-a-second language (ESL) nursing students: Strategies for building verbal and written language skills. Journal of Cultural Diversity, 10(4), 113-117.

Healthy People 2010. (n.d.). Access to quality health service: Primary care (Focus area 1-8,para 4). Retrieved July 20,2009, from http://www.healthypeople,gov/document/HTML/Volume1/ 01 Access.htm\#_Toc 489432816

Intersegmental Committee of Academic Senates (ICAS) Task Force. (2000). ESL Students in California Public Higher Education. Retrieved October 17, 2008, from http://eric.ed.gov:80/ERICDocs/data/ericdocs2sq1/content 01/00000196/80/1b/f132.pdf 
Kang, S. (2006). Measurement of acculturation, scale formats, and language competence: Their implications for adjustment. Journal of Cross-Cultural Psychology, 37(6), 669-693.

Kennedy, H.P., Fisher, L., Fontaine, D., \& Martin-Holland, J. (2008). Evaluating diversity in nursing education: A mixed method study. Journal of transcultural Nursing, 19(4), 363-370.

Lujan, J. (2008). Linguistic and cultural adaptation needs of Mexican American nursing students related to multiple-choice tests. Journal of Nursing Education, 47(7), 327-330.

Noels, K.A., Pon, G., \& Clement, R. (1996). Language, identity, and adjustment: The role of linguistic self-confidence in the acculturation process. Journal of Language and Social Psychology, 15(3), 246-264.

Salamonson, Y., Everett, B., Koch, J., Andrew, S., \& Davidson, P.M. (2008). English-language acculturation predicts academic performance in nursing students who speak English as a second language. Research in Nursing \& Health, 31, 86-94.

Scarcella, R. (2003). Academic English: A conceptual framework (Tech. Rep. No. 2003-1). Irvine: University of California, Linguistic Minority Research Institute. Retrieved July 27,2009 , from http://www.lmri.ucsb.edu/publications/03 scarcella.pdf Schwartz, A. (2008). Changing the face of nursing. Retrieved October 17, 2008, from the University of California, San Francisco, Advancing Health Worldwide: 
A Strategic Plan Website: http://strategy.ucsf.edu/stories/changing-the-face-of-nursing/

Solorzano, R.W. (2008). High stakes testing: Issues, implications, and remedies for for English language learners. Review of Educational Research, 78(2), 260-329.

Sowden, C. (2003). Understanding academic competence in overseas students in the UK. English Language Teaching Journal, 54(4), 377-385.

U.S. Census Bureau. (2000). An older and more diverse nation by mid-century. Retrieved August 2, 2009, from http://www.census.gov/Press-Release/www/releases/archives/ Population/000419.html

U. S. Department of Health and Human Services. (2000). Healthy people 2010: Understanding and improving health. $2^{\text {nd }}$ ed. Washington, DC: U.S. Government Printing Office. Yoder. (2001). Bridging approach: Effective strategies for teaching diverse nursing students. Journal of Transcultural Nursing, 12(4), 319-325. 
From:

Sent:

To:

Cc:

Subject:
Cazmo Lukrich

Wednesday, August 05, 2009 7:58 PM

Diane Stuenkel

Phyllis Connolly

Fw: Manuscript Submission for Leah Lukrich

Dear Dr. Stuenkel,

The manuscript is submitted and the manuscript number is: User name is The manuscript is submitted

See you soon---well, not to soon.

Again, thank you so very much for devoting a part of your summer to helping me reach my goal.

sincerely,

Leah

Forwarded Message ----

From: "scroce@slackinc.com"

To:

Sent: Wednesday, August 5, 2009 7:26:57 PM

Subject: Manuscript Submission

You have successfully submitted your manuscript, English Language Acculturation and Academic Acievement Among Junior Year Nursing Students. Your Manuscript Number is:

Take note of this number for future reference. You can log on at any time to see the current status of your manuscript(s). The web address is and your username is

If you wish to contact the journal office, here's how:

Journal of Nursing Education

SLACK Incorporated

6900 Grove Road

Thorofare, NJ 08086

USA

The JOURNAL OF NURSING EDUCATION is supported almost solely by subscriptions from nurse educators like you. Your or your institution's support is important to us. Subscribe by going to www.slackinc.com/subscribetoday or requesting your library carry this valuable title.

Thank you for your submission.

Jaime Harker, ELS

Managing Editor

Journal of Nursing Education 
HiB. Comolly. $8 / 6$ Please replace my erlier 2 mususesipts with these two. The monusexpts Iqaveyox on $8 / 4$ had a number meltat was uncorsect.

Thark you forall Gow thisppost throsh

cleahoubes

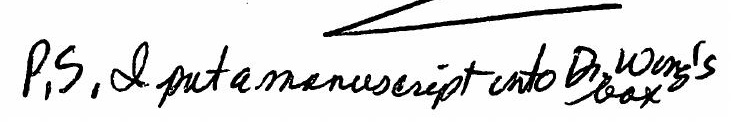

